\section{Greek university law defended}

SIR - I wish to comment on the letter from Emmanuel Papamichael (Nature 360, 704; 1992) on the new university law recently adopted by the Greek parliament. The letter is one-sided and misleading.

Before the law was introduced in the Greek parliament, there was an extremely long procedure during which the minister of education visited each Greek campus and held lengthy discussions with the universities' senates on the basis of written replies to a questionnaire distributed by the ministry to each member of the university community in Greece. It is therefore misleading to suggest that there has been "barely any debate".

Either by accident or design, Papamichael has also failed to mention several of the chief features of the new law. Thus it includes provisions for allowing the emergence of new institutions, one of which is the new open university aimed at providing extramural education for particular groups in Greek society and the foundation of a centre for the Greek language to coordinate the maintenance and dissemination of Greek in the European environment. Similarly, the law has made possible regulations to encourage the mobility of Greek university students within Europe. The arrangements for the accreditation of Greek universities is a new procedure aimed at rationalizing the distribution of funds according to objective criteria.

The new law also provides a simple and straightforward legal framework for the foundation of postgraduate courses, which have so far been weak and virtually nonexistent. Universities can now apply for funds to found postgraduate departments as well as to create academic research institutes linking universities with the industrial and business world.

At the same time, the new law provides that the previously free distribution of textbooks to all students be confined to needy students only. The funds set aside in this way will be used exclusively for departmental and central university libraries. Papamichael might have also mentioned that the number of scholarships and the funds available for them have been increased by 50 per cent and 500 per cent respectively.

Papamichael is also concerned with the status of existing academic personnel. But neither the old nor the new law provides tenure for the two lower academic grades. Papamichael may be right in saying that in Greece there is "very little employment in the private sector", but he fails to mention that only under the new law people who fail to get tenure at universities are now eligible for employment in the public sector. Moreover, it is not true that under the new law there is a freeze on promotions. Rather, the new law requires that academic positions be filled by responses to open advertisements and that the disciplines concerned be determined by the universities and not by the ministry. The ministry's power consists only of agreeing the number of places to be advertised, for which of course it has to pay the bill.

Papamichael's hope that the universities would have been overtaken by protests and that Greek scholars would have boycotted the examinations is wishful thinking. The universities are working normally under the new law.

Papamichael's account of the "private universities" is also inaccurate, as they are illegal under the Greek constitution. His comments on the absence of the minister from European meetings leaves no doubt of his one-sided and political approach to the problems of higher education in Greece.

\section{J.G. Antonopoulos}

(Secretary for Higher Education)

Ministry of National Education

and Religious Affairs,

Athens, Greece

\section{Copyright scam}

SIR - I am concerned at the cavalier way in which the copyrights of scientific papers are handed over to commercial publishers.

Increasingly the status and pay of scientists are determined by what they publish and by ratings in the Science Citation Index. Indeed they have to publish or perish ("Sure he was a great teacher, but what did he publish?") But in what other profession are the products of one's labour given away for nothing to people who then sell them?

I have been making a collection of the agreements that scientific authors are required to sign to get their papers published. I find some of them quite horrifying. Not only copyright, but all rights, are often signed away.

Twice recently, papers submitted to a journal have later appeared as sections of a book. The situation appears to be very different from that in the literary world, where, for example, copyrights of minor works by T. S. Eliot are objects of immense value. Copyright in chapters for a scientific textbook are often bought for sums that would hardly cover the cost of typing.

Dangerous conditions are sometimes attached. One publisher requires that authors warrant that the article does not infringe any copyright, trademark or patent, that it is not libellous and so on (matters that are beyond the competence of the author to judge) and the author is required to indemnify the publishers "against any costs, expenses, or damages which [the publisher] may incur or for which [the publisher] may become liable as a result of any breach of these warranties". The publisher has formed a limited liability company to protect himself from such contingencies but nevertheless has tried to pass this liability to the private individual. Whether an item is libellous or whatever depends on where it is circulated and this is under the control of the publisher and not of the author.

I think that authors requiring protection should assign copyrights to their institutions, or to the research council supporting the work, and inform the publisher that this body will give the publisher an exclusive licence to the material for perhaps two years. I have tried this a couple of times and have got away with it.

Publishers have to make an excepition for work produced by US government employees, where copyright is not transferred to the publishers, and this causes, I believe, no trouble at all.

With increasing commercialism, research councils and universities have a duty, I consider, to help to protect their authors in this matter.

\section{Alan Mackay}

Department of Crystallography,

Birkbeck College,

Malet Street, London WC1E 7HX, UK

\section{Tobacco code}

SIR - Because direct advertising of cigarettes is forbidden in Italy, it seems that other insidious strategies for cigarette promotion are being developed. But to my knowledge, never in the past has a Nobel prizewinner in medicine signed a promotion for Philip Morris Companies Inc. This year, however, new year greetings from Philip Morris, specifically addressed to the younger generation, occupied a whole page of the Italian newspaper La Repubblica on 31 December 1992, and included a message signed by the Nobel prizewinner Dr Rita Levi-Montalcini under the heading "Culture of the modern time". As a physician of Italian origin, I can only express a sense of surprise and shame which, I hope, is shared by the whole Italian biomedical community.

\section{Fablo Levi}

Vaud Cancer Registry,

Institut Universitaire de Médecine

Sociale et Préventive,

1011 Lausanne, Switzerland 